\title{
Microwave-Assisted Synthesis of Mono- and Disubstituted 4-Hydroxyacetophenone Derivatives via Mannich Reaction: Synthesis, XRD and HS-Analysis
}

\author{
Ghadah Aljohani ${ }^{1,3}$, Musa A. Said ${ }^{1, *}$, Dieter Lentz ${ }^{2}$, Norazah Basar ${ }^{3}$, Arwa Albar ${ }^{4} \oplus$, \\ Shaya Y. Alraqa ${ }^{1}$ and Adeeb Al-Sheikh Ali ${ }^{1, *}$ \\ 1 Chemistry Department, College of Science, Taibah University, P.O. Box 30002, \\ Al-Madinah Al-Munawarah 14177, Saudi Arabia; musa_said04@yahoo.co.uk (G.A.); \\ shaya97@hotmail.com (S.Y.A.) \\ 2 Institut für Chemie und Biochemie, Anorganische Chemie, Freie Universität Berlin, Fabeckstr. 34-36, \\ 14195 Berlin, Germany; dlentz@zedat.fu-berlin.de \\ 3 Department of Chemistry, Faculty of Science, Universiti Teknologi Malaysia, Johor Bahru 81310, Malaysia; \\ norazahb@utm.my \\ 4 Department of Physics, College of Science, Jeddah University, P.O. BOX 80327, Jeddah 21589, Saudi Arabia; \\ arwa.albar@kaust.edu.sa \\ * Correspondence: musa_said04@yahoo.co.uk (M.A.S.); AdeebAli@Dal.Ca (A.A.-S.A.); \\ Tel.: +966-595-883-585 (M.A.S.)
}

Academic Editor: John Spencer

Received: 23 December 2018; Accepted: 2 February 2019; Published: 7 February 2019

\begin{abstract}
An efficient microwave-assisted one-step synthetic route toward Mannich bases is developed from 4-hydroxyacetophenone and different secondary amines in quantitative yields, via a regioselective substitution reaction. The reaction takes a short time and is non-catalyzed and reproducible on a gram scale. The environmentally benign methodology provides a novel alternative, to the conventional methodologies, for the synthesis of mono- and disubstituted Mannich bases of 4-hydroxyacetophenone. All compounds were well-characterized by FT-IR, ${ }^{1} \mathrm{H}$ NMR, ${ }^{13} \mathrm{C}$ NMR, and mass spectrometry. The structures of 1-\{4-hydroxy-3-[(morpholin-4-yl)methyl]phenyl\}ethan-1-one (2a) and 1-\{4-hydroxy-3-[(pyrrolidin-1-yl)methyl]phenyl\}ethan-1-one (3a) were determined by single crystal X-ray crystallography. Compound $2 \mathbf{a}$ and 3a crystallize in monoclinic, $P 2_{1} / n$, and orthorhombic, $\mathrm{Pbca}$, respectively. The most characteristic features of the molecular structure of $\mathbf{2 a}$ is that the morpholine fragment adopts a chair conformation with strong intramolecular hydrogen bonding. Compound 3a exhibits intermolecular hydrogen bonding, too. Furthermore, the computed Hirshfeld surface analysis confirms $\mathrm{H}$-bonds and $\pi-\pi$ stack interactions obtained by XRD packing analyses.
\end{abstract}

Keywords: Mannich bases; 4-hydroxyacetophenone; microwave irradiation; regioselectivity; X-ray; HSA

\section{Introduction}

Mannich bases can be easily transformed into numerous compounds due to their high reactivity. Several Mannich bases are of particular interest due to their importance as precursors of valuable pharmaceuticals products and their use as synthetic building blocks [1,2]. Mannich bases have attracted more and more attention from chemists due to their specific biological activities, such as antiviral [3,4], acetylcholinesterase inhibitory [5-7], antioxidant [8,9], and antiproliferative $[10,11]$ 
activity. Mannich bases are also key precursors to accessing amino alcohols, peptides, lactams, and optically active amino acids $[12,13]$. Consequently, many researchers were attracted to investigating green protocols for the Mannich reaction during the last period [2]. The Mannich reaction is an essential reaction for the direct formation of new $\mathrm{C}-\mathrm{C}$ and $\mathrm{C}-\mathrm{N}$ bonds $[10,14]$. The products of Mannich reaction of 4-hydroxyacetophenone as substrate vary depending on the reaction conditions. Using classical conditions, such as low $\mathrm{pH}$, the acetyl group undergoes reaction, producing $\beta$-amino alkyl ketone. In this case, the substrate is converted into the corresponding Mannich base through an aminomethylation process. On the other hand, under an alkaline medium, the Mannich reaction is selectively undergoes electrophilic aromatic substitution in the ortho position to the hydroxyl group (Scheme 1) [1]. The conventional multicomponent Mannich reactions are found to have drawbacks such as a long reaction time, harsh reaction conditions, and toxic vapor and byproducts [15]. As a consequence, different reaction conditions have been widely described for Mannich reaction in the presence of a variety of catalysts [16,17]. Additionally, a continuous search for the synthetic methodologies of cleaner Mannich reactions seeking green chemistry principles includes the use of protocols in water [14], biodegradable and reusable catalysts $[18,19]$, ionic liquids $[12,19,20]$, and solvent-free and/or catalyst-free media reaction conditions under microwave (MW) and ultrasound irradiation [21-27]. Microwave irradiation has been used to synthesize a lot of organic compounds. In fact, the use of microwave irradiation offers a higher reaction rate and better product in chemical synthesis [28], however, few studies have been done utilizing microwave irradiation in the synthesis of Mannich bases [21,25]. These studies were done under acidic conditions using substituted acetophenones whereas the regioselectivity of the reaction was studied on the 2-hydroxy-chalcone backbone [29]. Hence, we describe, herein, the first efficient, gram-scale, non-catalyzed and microwave-assisted synthetic approach of mono- and disubstituted Mannich bases of para-hydroxyacetophenone with various secondary amines.

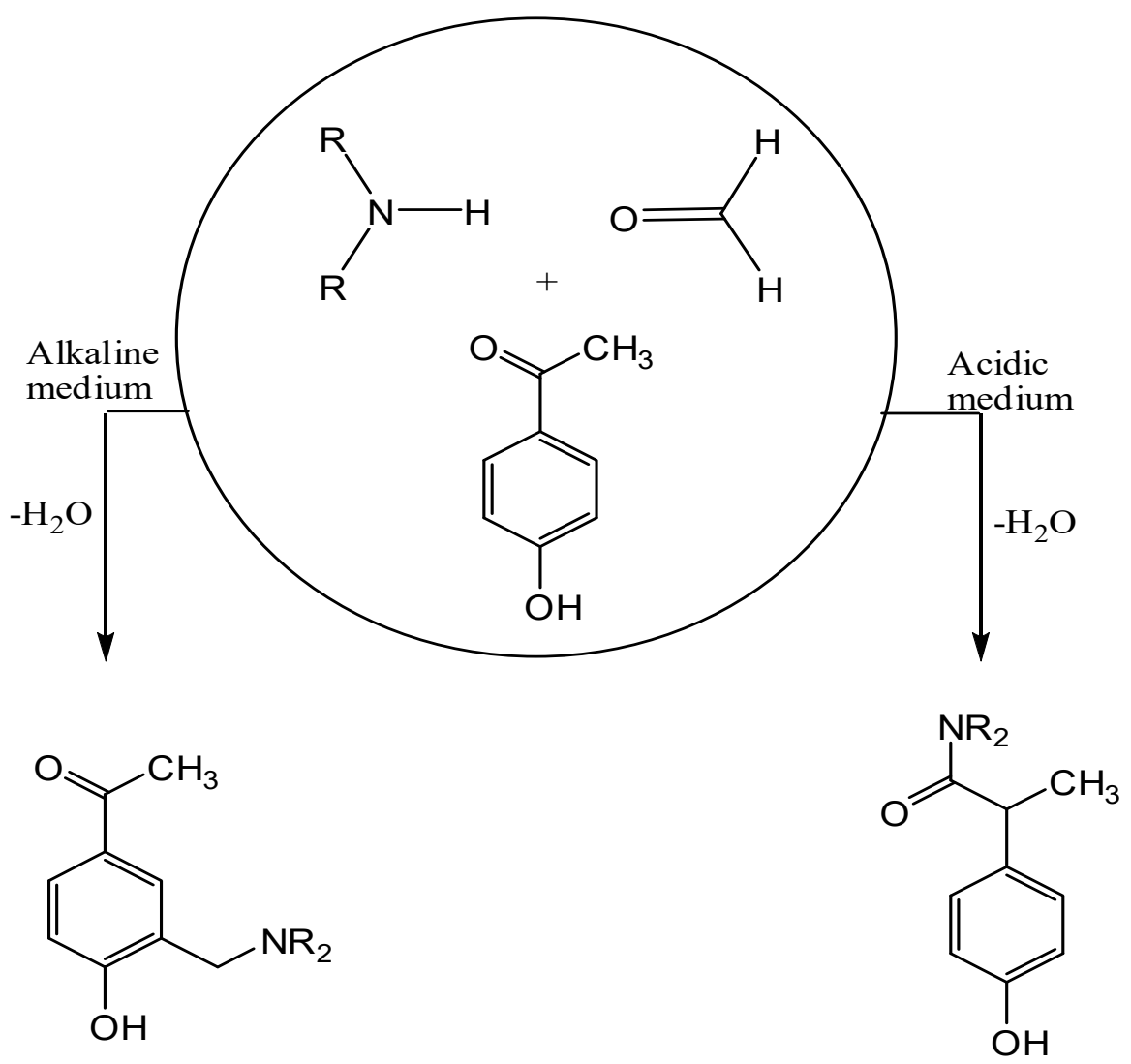

Scheme 1. Possible products of Mannich-type reaction using classical conditions. 


\section{Results and Discussion}

\subsection{General Synthesis}

Firstly, the reactions were run in small scales $(2 \mathrm{mmol})$ of 4-hydroxyacetophenone with different ratios of morpholine as a model reaction, to find out the optimal conditions in terms of solvent, time, reactant ratio, and temperature. Four different solvents, namely, water, ethanol, ethylene glycol, and 1,4-dioxane, at fixed power $(300 \mathrm{~W})$ were used for optimization. The temperature ranged between 100 and $120{ }^{\circ} \mathrm{C}$, higher than the boiling points of the chosen solvent as the experiments were done in a sealed vessel. When water was used as a solvent, the corresponding product was not observed based on the TLC monitoring and the reaction led to the formation of an insoluble product in classical organic solvents. On the other hand, using polar protic solvents (ethanol or ethylene glycol) gave the corresponding monosubstituted Mannich product 2a at a very low yield. Interestingly, an excellent yield was obtained when 1,4-dioxane was used as a solvent. The TLC showed complete consumption of 4-hydroxyacetophenone after $30 \mathrm{~min}$ by disappearance of the starting material spot, and two new main spots were observed using 1.5 equivalents of formaldehyde and morpholine as a model for optimization (Scheme 2).

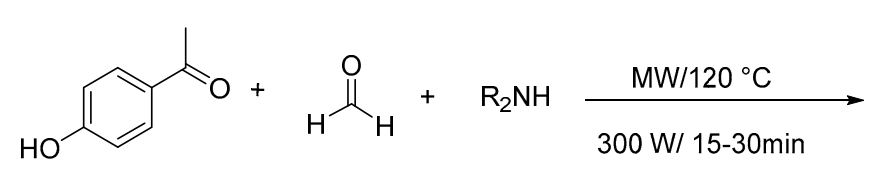

1<smiles>[R20]NCc1cc(C(C)=O)cc(CN[R10])c1O</smiles>

2a

2b

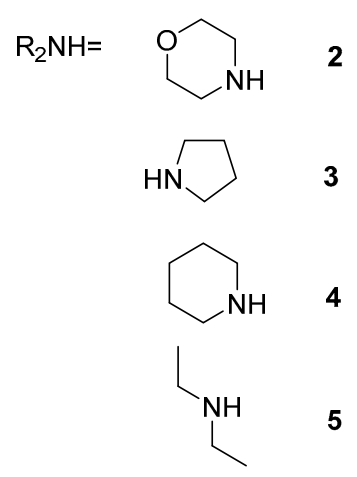

Scheme 2. Synthetic approach for synthesis of mono- and disubstituted Mannich bases of 4-hydroxyacetophenone (1).

The resulting mixture was purified via column chromatography. The first eluted compound was characterized using spectroscopic analysis. The ${ }^{1} \mathrm{H}$ NMR analysis of compound $\mathbf{2 a}$ showed the disappearance of one of the aromatic protons, revealing regioselective monosubstitution on the aromatic ring. ${ }^{1} \mathrm{H}$ NMR exhibits a broad singlet at $3.78 \mathrm{ppm}$ integrated to six protons related to the benzylic protons which overlapped with four protons in $\left(\mathrm{OCH}_{2}\right)$ related to morpholine moiety. A multiplet peak, between 2.54 and 2.59 ppm, was assigned to the protons in $\left(\mathrm{NCH}_{2}\right)$ in the morpholine moiety and the methyl group. The ${ }^{13} \mathrm{C}$ spectrum verified the formation of Mannich base $2 \mathrm{a}$ due to the presence of three peaks of $\mathrm{CH}_{2}$ group related to $\left(\mathrm{NCH}_{2}\right)$ at $52.74 \mathrm{ppm}$, benzylic $\left(\mathrm{CH}_{2}\right)$ at $61.24 \mathrm{ppm}$, and $\left(\mathrm{OCH}_{2}\right)$ of morpholine moiety at $66.52 \mathrm{ppm}$. Moreover, the presence of only three resonances for the aromatic $\mathrm{CH}$ at 116.07, 129.75, and 130.56 ppm confirmed the formation of monosubstituted Mannich base. On the other hand, the ${ }^{1} \mathrm{H}$ NMR spectral analysis of the second compound showed the formation of disubstituted Mannich product $\mathbf{2 b}$. As a result, two protons disappeared in the aromatic region and the integration of two morpholine moieties to the other protons confirmed the formation of $\mathbf{2 b}$. The ${ }^{13} \mathrm{C}$ exhibit a single resonance of two equivalent aromatic $\mathrm{CH}$ at $130.24 \mathrm{~m}$ confirming the occurrence of 
disubstitution reaction at the benzene ring. Meanwhile, the mass spectral data are in agreement with the molecular formula of $\mathbf{2 a}$ and $\mathbf{2} \mathbf{b}$. Due to the successful results, a gram-scale (16 mmol) experiment was run for morpholine to determine the overall yield of both $\mathbf{2} \mathbf{a}$ and $\mathbf{2} \mathbf{b}$.

Comparing the conventional method to the microwave radiation, it was found that the reaction time decreased considerably from $22 \mathrm{~h}$, using thermal heating, to $30 \mathrm{~min}$ in order to furnish monoand/or disubstituted Mannich bases $\mathbf{2 a}$ and $\mathbf{2 b}$ in quantitative yield [30]. Using the same optimized conditions (power, solvent, temperature, and reactant ratio) for the formation of mono- or disubstituted Mannich bases, compounds $\mathbf{3 a}-\mathbf{5 a}$ and $\mathbf{3 b}-\mathbf{4 b}$ were synthesized after $15 \mathrm{~min}$ in overall yields of $64 \%$ to 77\% (Table 1, Supplementary Materials). The time was monitored for each amine based on TLC results.

Table 1. Mannich bases derivatives 2a/ b-5a under microwave irradiation $\left(300 \mathrm{~W}, 120^{\circ} \mathrm{C}\right.$ using dioxane as solvent).

Compound

In order to improve the product ratios, different reactant ratios were used in 1,4-dioxane at $120{ }^{\circ} \mathrm{C}$ (which was found to be the optimal reaction temperature) and $300 \mathrm{~W}$. It was found that the monosubstituted Mannich base 2a was obtained as a major product ( $80 \%$ after column) when 1.5 equivalent of the secondary amine and formaldehyde were used. However, the disubstituted Mannich base $\mathbf{2 b}$ was formed quantitively as the only product when 2 equivalents of the secondary amine and formaldehyde were used (Table 1, Supplementary Materials). The product yield was greatly increased in quantitative yield, compared to the $60 \%$ that had been obtained before [30]. For the novel compounds $3 b$ and $4 b$, the yield under the same conditions was $86 \%$ and $94 \%$, respectively. It should be noted that the diethylamine used did not undergo disubstituted Mannich reaction under the same conditions and only monosubstituted 5a was obtained but in nearly quantitative yield. This may be due to the free rotation of diethyl groups that might sterically prevent the occurrence of disubstituted reaction in comparison to the rigid cyclic secondary amines.

\subsection{Crystal Structure Description}

The structures of the monosubstituted compounds $2 \mathbf{a}$ and $3 \mathbf{a}$ were proposed on the basis of ${ }^{1} \mathrm{H}$ and ${ }^{13} \mathrm{C}$ NMR, and IR spectroscopic analyses. In order to gain information on their structural characteristics, X-ray crystallographic analyses were carried out for both 2a and 3a [31-37]. The molecular structures and some atom-numbering schemes are depicted in Figures 1 and 2 for $2 \mathbf{a}$ and $3 \mathbf{a}$ respectively. Crystallographic data and structure refinement parameters for $\mathbf{2 a}$ and $\mathbf{3 a}$ are listed in Table 2. Selected bond lengths, angles, and torsion angles are listed in Tables 3 and 4. 
The most characteristic feature of the molecular structure of $2 \mathbf{a}$ is that the morpholine fragment adopts a chair conformation with strong intramolecular hydrogen bonding. One carbon atom of the chair conformation deviates from the main plane by only $0.015 \AA$, indicating an almost perfect chair conformation for the morpholine fragment. The acetyl substituent is located almost in the plane of the aromatic with a torsion $\mathrm{C} 5-\mathrm{C} 4-\mathrm{C} 12-\mathrm{O} 3$ of $1.6^{\circ}$. However, the morpholino substituent is turned out of the ring plane resulting in $\mathrm{C} 1-\mathrm{C} 2-\mathrm{C} 7-\mathrm{N} 1$ of $-45.7^{\circ}$. There exists only one intramolecular hydrogen bond of $\mathrm{H} 1$ to the nitrogen atom N1 (O1 .. N1 2.634 (2) with a normalized [38,39] O-H of $0.938 \AA$, resulting in a N . . . H distance of 1.801 and an $\mathrm{O} 1-\mathrm{H} 1-\mathrm{N} 1$ angle of $146.5^{\circ}$ ). No intermolecular hydrogen bonds can be detected for $\mathbf{2 a}$.

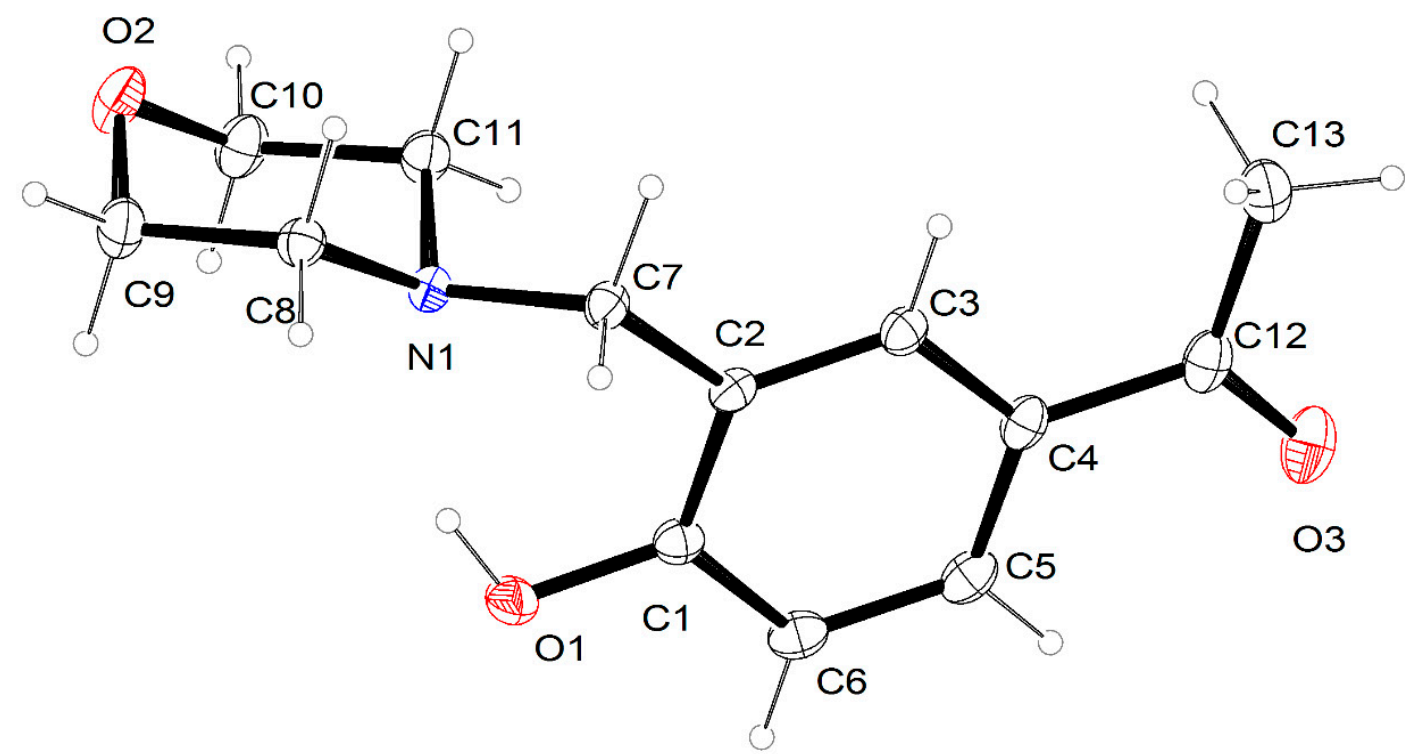

Figure 1. An ORTEP $[34,35]$ drawing of 2 a with an atom-numbering scheme. The thermal ellipsoids are drawn at the $50 \%$ probability level.

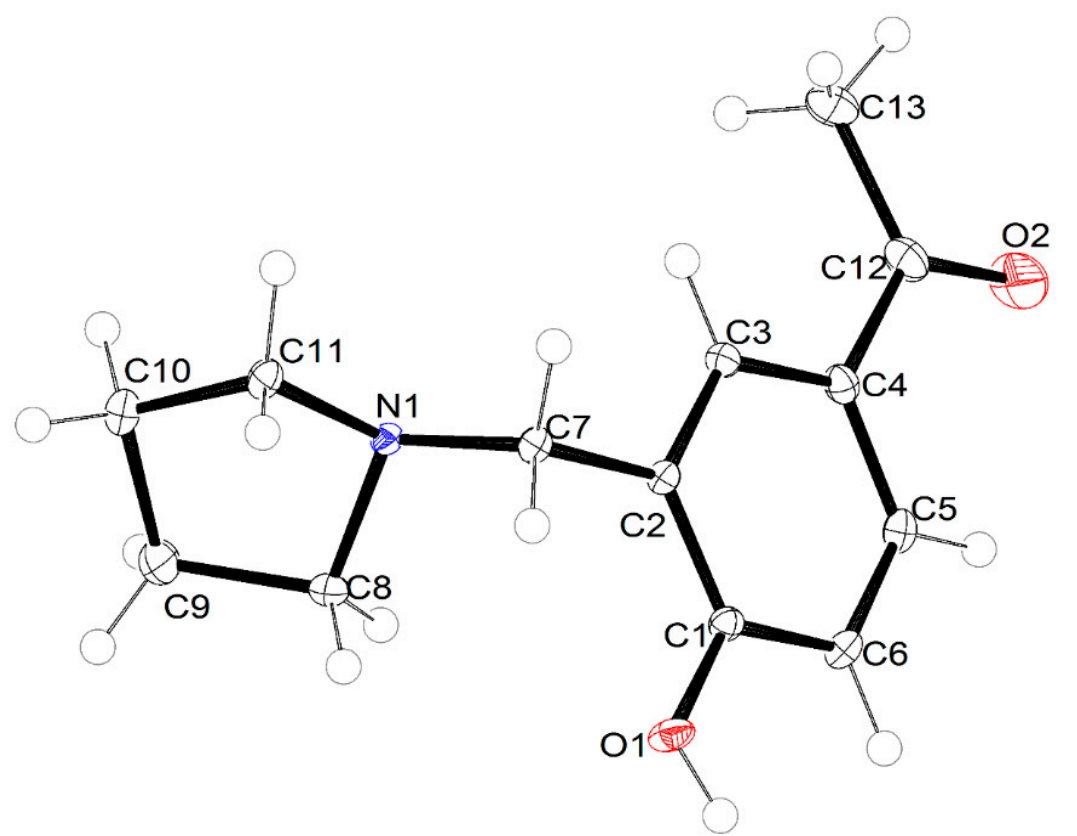

Figure 2. ORTEP $[34,35]$ and numbering scheme of $\mathbf{3 a}$, thermal ellipsoids are drawn at the $50 \%$ probability level. 
Table 2. Crystallographic data and structure refinement parameters for $\mathbf{2 a}$ and $3 \mathbf{a}$.

\begin{tabular}{|c|c|c|}
\hline Compound & $2 a$ & $3 \mathbf{a}$ \\
\hline Chemical formula & $\mathrm{C}_{13} \mathrm{H}_{17} \mathrm{NO}_{3}$ & $\mathrm{C}_{13} \mathrm{H}_{17} \mathrm{NO}_{2}$ \\
\hline$M_{\mathrm{r}}$ & 235.27 & 219.27 \\
\hline Crystal system, space group & Monoclinic, $P 2_{1} / n$ & Orthorhombic, $\mathrm{Pbca}$ \\
\hline Temperature (K) & $100(2)$ & $100(2)$ \\
\hline $\mathrm{a}, \mathrm{b}, \mathrm{c}(\AA)$ & 7.297 (6), 11.375 (8), 14.571 (12) & 10.8735 (8), $10.9988(9), 19.0645$ \\
\hline$\beta\left(^{\circ}\right)$ & $93.79(3)$ & \\
\hline$V\left(\AA^{3}\right)$ & $1206.9(16)$ & $2280.0(3)$ \\
\hline Z & 4 & 8 \\
\hline Radiation type & Mo $K \alpha$ & Mo $K \alpha$ \\
\hline$\mu\left(\mathrm{mm}^{-1}\right)$ & 0.09 & 0.09 \\
\hline Crystal size (mm) & $0.50 \times 0.40 \times 0.35$ & $0.44 \times 0.18 \times 0.17$ \\
\hline \multicolumn{3}{|l|}{ Data collection } \\
\hline Diffractometer & Bruker D8 Venture Photon & Bruker D8 Venture Photon \\
\hline Absorption correction & $\begin{array}{c}\text { Multi-scan } S A D A B S 2016 / 2 \\
\text { (Bruker AXS) }\end{array}$ & $\begin{array}{c}\text { Multi-scan } S A D A B S 2016 / 2 \\
\text { (Bruker AXS) }\end{array}$ \\
\hline$T_{\min }, T_{\max }$ & $0.879,0.928$ & $0.879,0.928$ \\
\hline $\begin{array}{l}\text { No. Of measured, independent } \\
\text { and observed }[I>2 \sigma(I)] \text { reflections }\end{array}$ & $28902,3719,3447$ & $86662,3500,3186$ \\
\hline$R_{\text {int }}$ & 0.025 & 0.034 \\
\hline$(\sin \theta / \lambda)_{\max }\left(\AA^{-1}\right)$ & 0.717 & 0.650 \\
\hline \multicolumn{3}{|l|}{ Refinement } \\
\hline$R\left[F^{2}>4 \sigma\left(F^{2}\right)\right], w R\left(F^{2}\right), S$ & $0.034,0.095,1.03$ & $0.037,0105,1.054$ \\
\hline No. Of reflection & 3719 & 3500 \\
\hline No. Of parameters & 157 & 147 \\
\hline H-atom treatment & $\mathrm{H}$-atom parameters constrained & $\mathrm{H}$-atom parameters constrained \\
\hline$\Delta \rho_{\max }, \Delta \rho_{\min }\left(\mathrm{e}^{-3}\right)$ & $0.41,-0.20$ & 0.39 and -0.308 \\
\hline
\end{tabular}

Computer programs: Bruker APEX3, Bruker SAINT [31], SHELXT 2014/5, [32,33].

Table 3. Geometric parameters $\left(\AA,^{\circ}\right)$ for compound 2 a.

\begin{tabular}{cccc}
\hline O1-C1 & $1.3539(13)$ & C11-C10 & $1.5160(14)$ \\
O1-H1 & 0.8400 & N1-C11 & $1.4675(15)$ \\
O2-C10 & $1.4209(12)$ & N1-C7 & $1.4759(13)$ \\
O2-C9 & $1.4241(15)$ & C1-C6 & $1.3959(14)$ \\
O3-C12 & $1.2208(13)$ & C1-C2 & $1.4048(13)$ \\
N1-C8 & $1.4633(12)$ & C12-C13 & $1.5031(15)$ \\
C10-O2-C9 & $110.06(7)$ & O3-C12-C4 & $120.84(8)$ \\
C8-N1-C11 & $109.45(7)$ & O3-C12-C13 & $120.05(9)$ \\
C8-N1-C7 & $110.34(7)$ & C4-C12-C13 & $119.09(8)$ \\
C11-N1-C7 & $111.90(7)$ & C5-C6-C1 & $119.33(8)$ \\
O1-C1-C6 & $119.13(7)$ & C6-C5-C4 & $121.58(8)$ \\
O1-C1-C2 & $120.61(7)$ & C3-C2-C1 & $119.27(7)$ \\
N1-C8-C9 & $109.95(7)$ & N1-C11-C10 & $109.34(7)$ \\
N1-C7-C2 & $111.38(6)$ & O2-C9-C8 & $111.10(7)$ \\
\hline
\end{tabular}

Table 4. Geometric parameters $\left(\AA{ }^{\circ},{ }^{\circ}\right.$ for compound 3a.

\begin{tabular}{cccc}
\hline O1-C1 & $1.3381(9)$ & C6-H6 & 0.9500 \\
O1-H1 & 0.8400 & C5-H5 & 0.9500 \\
N1-C7 & $1.4777(10)$ & C8-C9 & $1.5386(12)$ \\
N1-C11 & $1.4781(10)$ & O2-C12 & $1.2226(12)$ \\
N1-C8 & $1.4817(10)$ & C3-C2 & $1.3924(10)$ \\
C7-N1-C11 & $112.43(6)$ & N1-C11-C10 & $102.67(6)$ \\
C7-N1-C8 & $113.93(6)$ & O2-C12-C4 & $120.57(8)$ \\
C11-N1-C8 & $103.46(6)$ & O2-C12-C13 & $120.09(8)$ \\
O1-C1-C2 & $118.31(7)$ & N1-C7-C2 & $112.27(6)$ \\
C3-C2-C1-O1 & $177.70(7)$ & C7-C2-C1-O1 & $-1.46(11)$ \\
C11-N1-C7-C2 & $-169.16(6)$ & C7-N1-C8-C9 & $162.59(7)$ \\
C8-N1-C7-C2 & $73.55(8)$ & C8-N1-C11-C10 & $-46.12(7)$ \\
C3-C2-C7-N1 & $80.26(9)$ & C3-C4-C12-O2 & $173.05(9)$ \\
C1-C2-C7-N1 & $-100.58(8)$ & C5-C4-C12-O2 & $-6.28(13)$ \\
\hline
\end{tabular}


By contrast, compound 3a exhibits intermolecular hydrogen bonding. Another interesting structural aspect in 3a is related to the molecular packing stability. It is documented that intermolecular hydrogen bonding plays a significant role in the assembling of molecules into a well-ordered crystal packing structure. This is because intermolecular hydrogen bonding helps to form a network (Figure 3) [40,41]. It is worth mentioning that heterocycles containing a pyrrolidine moiety are frequently found in many bioactive compounds [42]. The pyrrolidine ring in 3a has a slightly twisted envelop conformation with a deviation of the C11 atom from the main plane of C8, C9 and C10 by $0.234 \AA$ (Figure 2), indicating that the pyrrolidine ring has some ring strain [42]. The N1 atom is found above this main plane by $0.444 \AA$ (Figure 2). On the other side, the angles around N1 of $114.80^{\circ}$, $103.19^{\circ}$, and $112.90^{\circ}$ indicating a distorted tetrahedral geometry around the central atom N1.

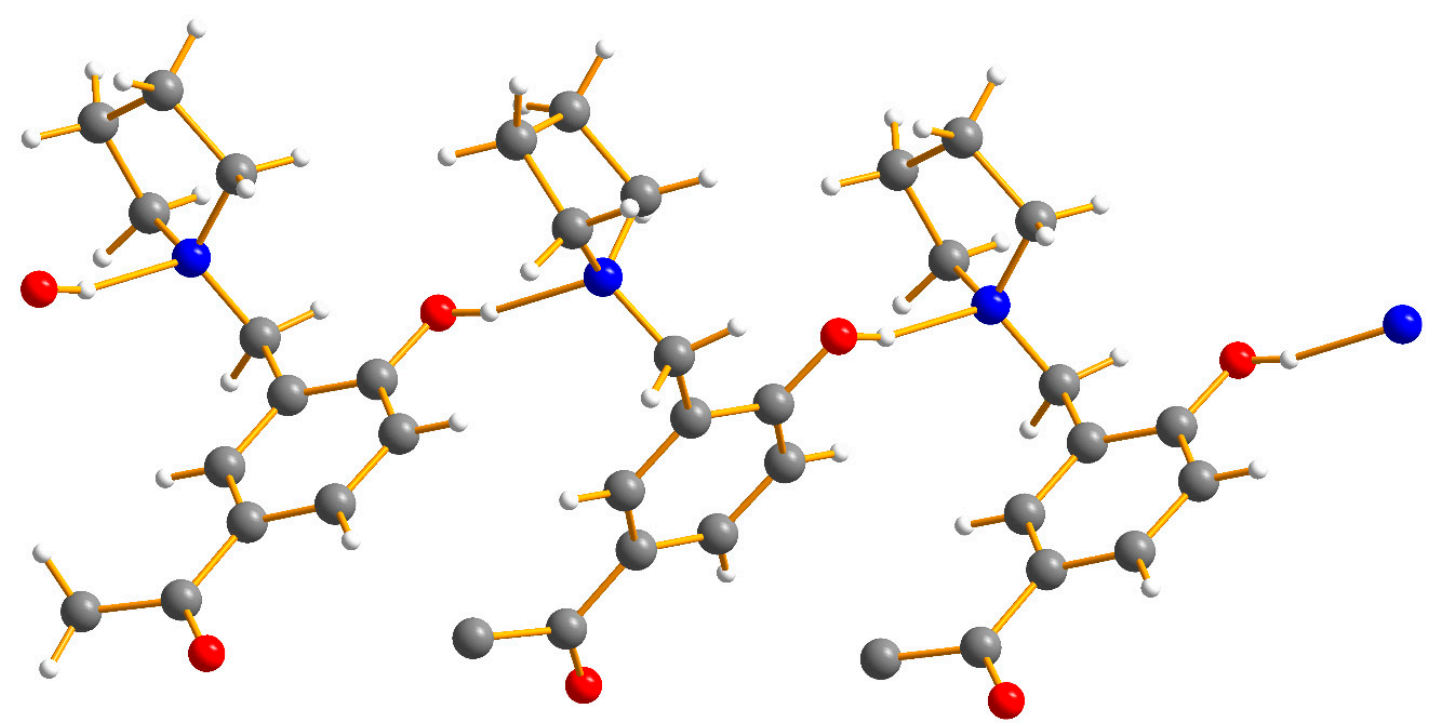

Figure 3. Intermolecular hydrogen bond network of 3a (Diamond [36]). View along the a-axis.

\subsection{Hirshfeld Analysis}

The Hirshfeld surface analysis (HSA), mapped over $\mathrm{d}_{\text {norm }}$ and shape index plots, are illustrated in Figure $4 \mathbf{a}, \mathbf{b}$ for compounds $\mathbf{2 a}$ and $\mathbf{3 a}$, respectively. Table 5 summarizes the relative contributions of different atomic contacts to the HSs. The $d_{\text {norm }}$ surface of $2 \mathbf{a}$ compound (ranging from $-0.259 \AA$ to $1.364 \AA)$ shows two deep red spots related to $\mathrm{H}$. . . O (2.267 $\AA$ ) and H . . H $(2.767 \AA)$, indicating strong short contacts. The $\mathrm{H}$... H interaction is found to be dominating for the $\mathbf{2 a}$ compound, accounting for $55.8 \%$ of $\mathrm{HS}$ area, whereas $\mathrm{H} \ldots \mathrm{O} / \mathrm{O} \ldots \mathrm{H}$ contact accounted for $12.6 \%$ and $14.8 \%$ of HS area. The white spots on HS are mainly due to $\mathrm{H}$... H contact. Shape index plot for $2 \mathrm{a}$ compound shows adjacent red and blue triangle (red-dash circle) indicating the presence of $\pi-\pi$ stacking. The $d_{\text {norm }}$ surface of 3a (ranging from $-0.758 \AA$ to $1.239 \AA$ ) shows two deep red spots related to O-H ... N/N ... H-O strong short contacts (due to distances of $1.657 \AA / 2.132 \AA$ ), which accounted for only $1.6 \%$ of HS area. Most of the white spots on the shape index surface are due to $\mathrm{H}$... H contacts, which contribute with $60.7 \%$ to HS area. The zero contribution of C . . C interaction to HS for 3a compound indicates the absence of $\pi-\pi$ stacking. This is in agreement with that shown by XRD. The $\pi-\pi$ stacking distance, in 3a, is measured as the distance between the aromatic centroids. The X-ray structure of 3a shows a separation of $6.183 \AA$ between the aromatic centroids. Shape index plots for $\mathbf{2 a}$ and $3 \mathbf{a}$ show red concave and blue convex areas, which characterize the packing mode with nearby molecules (Figure 4). 

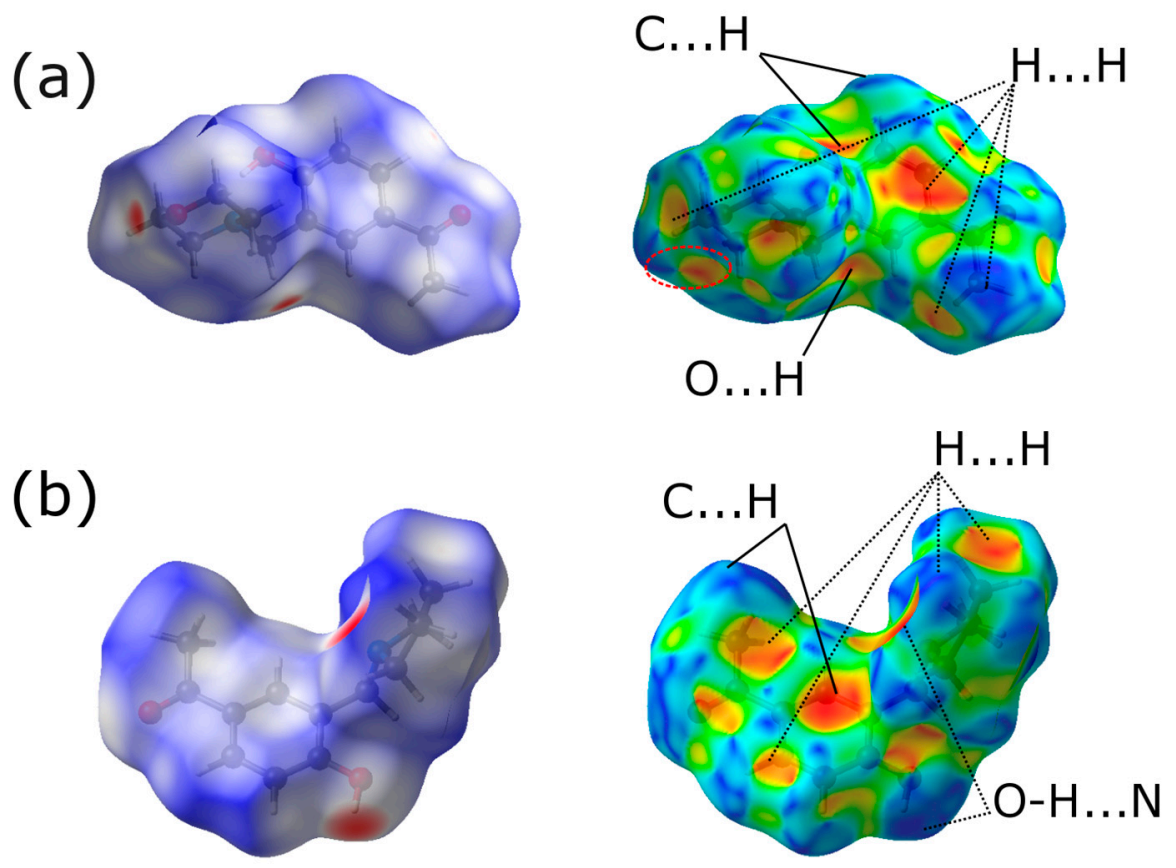

Figure 4. Hirshfeld surfaces mapped with $d_{\text {norm }}$ (left) and sharp index (right) for (a) 2a and (b) 3a compounds.

Table 5. Relative contributions of internal and external atomic contacts to the Hirshfeld surface for 2a and $3 \mathbf{a}$ compounds.

\begin{tabular}{ccc}
\hline Contact & Percentage in 2a & Percentage in 3a \\
\hline H . . H & $55.8 \%$ & $60.7 \%$ \\
H . O & $12.6 \%$ & $7.9 \%$ \\
O . . H & $14.8 \%$ & $9.4 \%$ \\
C . C & $0.9 \%$ & $0.0 \%$ \\
N . . H H . . N & $0.0 \%$ & $1.6 \%$ \\
H . . C & $6.7 \%$ & $10.3 \%$ \\
C . H & $8.8 \%$ & $8.3 \%$ \\
O . . C C . O & $0.0 \%$ & $0.1 \%$ \\
\hline
\end{tabular}

Figure 5 shows the 2D fingerprint plots for the overall compounds, as well as for specific contacts. The $\mathrm{H}$... H interaction is indeed the dominating one for $\mathbf{2 a}$ and $3 \mathbf{a}$ compounds. The comparable wings of $\mathbf{2 a}$ and $3 \mathbf{a}$ fingerprint plots, which are due to $\mathrm{C} \ldots \mathrm{H} / \mathrm{H} \ldots \mathrm{C}$ contacts, indicate similarity between the two compounds. C ... H/H . . C contact acts as a secondary interaction with no significant peaks. For $2 \mathbf{a}$, the red-dash circle indicates the $0.9 \%$ contribution of $\pi-\pi$ stacking. While $\mathrm{O}-\mathrm{H} \ldots$ $\mathrm{N} / \mathrm{N} \ldots \mathrm{H}-\mathrm{O}$ contact plays a critical role in $\mathbf{3 a}$ compound, it is completely absent in the $\mathbf{2} \mathbf{a}$ compound. The two small side peaks obtained for $2 \mathrm{a}$ compound are due to $\mathrm{O} \ldots \mathrm{H} / \mathrm{H} \ldots \mathrm{O}$ contact with tips at $d_{i}+d_{e}=2.25 \AA$. However, the shortest contact is obtained by the middle peaks (with tips at $d_{i}+$ $\left.\mathrm{d}_{\mathrm{e}}=2.2 \AA\right)$, which are due to $\mathrm{H} \ldots \mathrm{H}$ contact, indicating strong $\mathrm{H} \ldots \mathrm{H}$ interaction. Interestingly, two distinct sharp spikes are obtained for $3 a$, which are due to considerably short $\mathrm{O}-\mathrm{H} \ldots \mathrm{N} / \mathrm{N} \ldots$ $\mathrm{H}-\mathrm{O}$ contacts, indicating strong molecular interaction. The corresponding $\mathrm{d}_{\mathrm{i}}$ and $\mathrm{d}_{\mathrm{e}}$ combination are $0.65 \AA$ and $1.05 \AA$ with tips at $d_{i}+d_{e}=1.7 \AA$. Consequently, HAS findings are in agreement with XRD packing analyses. 
(a)
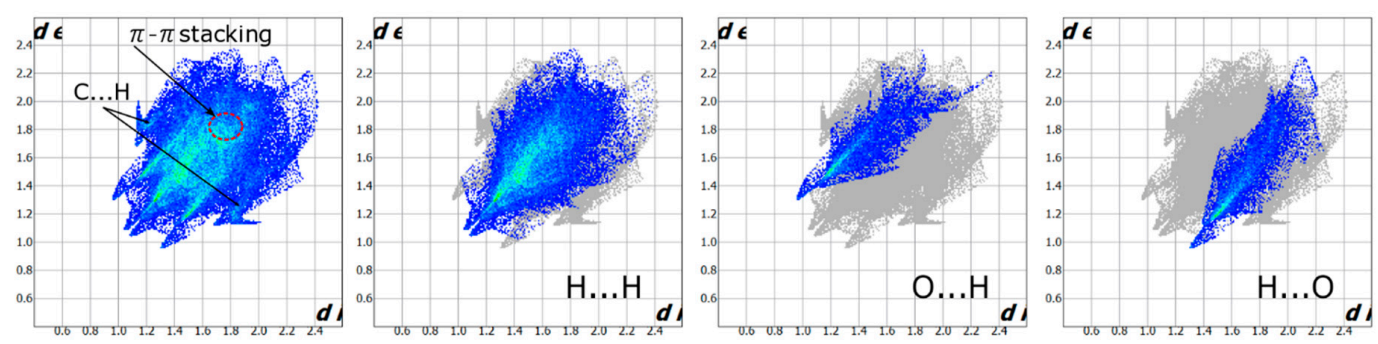

(b)
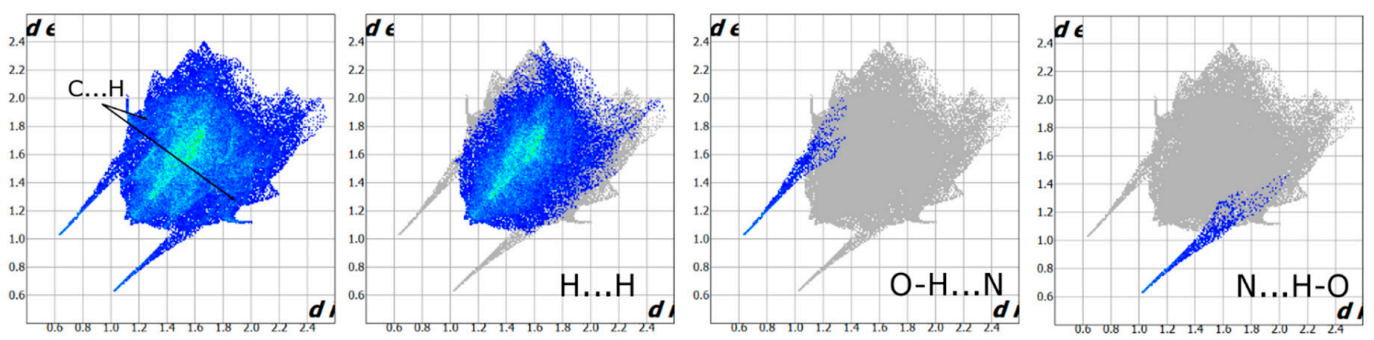

Figure 5. 2D fingerprint plots for (a) 2a and (b) 3a: full (left) and then resolved into $\mathrm{H} \ldots \mathrm{H}, \mathrm{O} \ldots$ $\mathrm{H} / \mathrm{H} \ldots \mathrm{O}$, and $\mathrm{O}-\mathrm{H} \ldots \mathrm{N} / \mathrm{N} \ldots \mathrm{H}-\mathrm{O}$ contacts.

\section{Materials and Methods}

All solvents and reagents were purchased from Sigma-Aldrich (Deisenhofen, Germany) and used without further purification. 4-Hydroxyacetophenone was purchased from Acros (Thermo Fisher Scientific Geel-Belgium). The monitoring of reaction was done by the utilization of pre-coated silica gel plates $\left(60 \mathrm{~F}_{254}\right)$ and thin layer chromatography (TLC). The normal phase silica gel (Merck, 70-230 mesh) was used to perform column chromatography purification, while the Merck silica gel (230-400 mesh) was utilized to perform the vacuum liquid chromatography.

A controllable single-mode microwave reactor, CEM Discover Microwave ${ }^{\mathrm{TM}}$ designed for synthetic utilization, was used. The reactor consists of power and pressure controls in addition to a magnetic stirrer. The temperature is controlled by an IR sensor. Melting points were measured using Sanyo MPD350 apparatus (Gallenkamp, Osaka, Japan) with digital display, and they were not corrected. A Perkin Elmer ATR spectrophotometer (Waltham, MA, USA) was used to record the infrared (IR) spectra. A Bruker Advance $400 \mathrm{MHz}$ spectrometer (Fällanden, Switzerland) was used to record ${ }^{1} \mathrm{H}$ NMR and ${ }^{13} \mathrm{C}$ NMR spectra. NMR samples were separately measured in DMSO, $\mathrm{CDCl}_{3}$, and $\mathrm{MeOD}$ at room temperature. Mass spectra were recorded on Finnigan MAT95XL (ThermoFisher Scientific, Bremen, Germany) using (EI), at $70 \mathrm{eV}$.

\subsection{General Synthesis of Mannich Bases (2-5)}

To a solution of 4-hydroxy-acetophenone (1) $(16 \mathrm{mmol}, 2.18 \mathrm{~g}$ ) and formaldehyde (24 mmol or $32 \mathrm{mmol}$ ) in 1,4-dioxane (15 mL), the corresponding secondary amine (morpholine (2), pyrrolidine (3), piperidine (4) or diethylamine (5)) was added using the same ratio of formaldehyde. This mixture was placed in the MW sealed vessel with stirring. The reaction mixture was irradiated for 15-30 min at $120^{\circ} \mathrm{C}$ (power $300 \mathrm{~W}$ ). TLC was used to monitor the progress of the reaction. After consumption of the starting materials, the vessel was removed and cooled down to room temperature. The reaction mixture was concentrated under reduced pressure and purified using column chromatography.

\subsubsection{1-\{4-Hydroxy-3-[(morpholin-4-yl)methyl]phenyl\}ethan-1-one (2a)}

The purification of the crude product, which has been synthesized in the respective ratio of 1:1.5:1.5 of compound 1, formaldehyde, and morpholine, was done using column chromatography with hexanes/EtOAc (8:2) as eluent to yield 2a as colorless crystals $(3.02 \mathrm{~g} ; 80 \%), \mathrm{mp} 69-70{ }^{\circ} \mathrm{C}$. IR spectrum $\left(v_{\max } / \mathrm{cm}^{-1}\right): 1110(\mathrm{C}-\mathrm{N}), 1246(\mathrm{C}-\mathrm{O}), 1581(\mathrm{C}=\mathrm{C}), 1666(\mathrm{C}=\mathrm{O}), 2978\left(\mathrm{CH}_{3}, \mathrm{sp}^{3}\right) .{ }^{1} \mathrm{H}$ NMR (ppm/ $\left., 400 \mathrm{MHz}, \mathrm{CDCl}_{3}\right): 2.59-2.54(\mathrm{~m}, 7 \mathrm{H}), 3.77(\mathrm{br} \mathrm{s}, 6 \mathrm{H}), 6.85(\mathrm{~d}, J=8.5 \mathrm{~Hz}, 1 \mathrm{H}), 7.69(\mathrm{~s}, 1 \mathrm{H}), 7.82$ 
$(\mathrm{d}, J=8.5 \mathrm{~Hz}, 1 \mathrm{H}), 11.32$ (br s, $1 \mathrm{H},-\mathrm{OH}) .{ }^{13} \mathrm{C} \mathrm{NMR}\left(\mathrm{ppm} / \delta, 100 \mathrm{MHz}, \mathrm{CDCl}_{3}\right) \delta 26.24,52.74,61.24$, $66.52,116.07,120.23,129.20,129.75,130.56,162.43,196.77$. EIMS, $m / z$ (\% rel. intensity): 235(100) $\left[\mathrm{M}^{+}\right.$, $\left.\mathrm{C}_{13} \mathrm{H}_{17} \mathrm{NO}_{3}\right], 204$ (16), 188 (38), 176 (12), 162 (20), 149 (76), 133 (18), 106 (10), 100 (10), 86 (45), 77 (21), 57 (22).

\subsubsection{1-\{4-Hydroxy-3,5-bis[(morpholin-4-yl) methyl]phenyl\}ethan-1-one (2b)}

The purification of the crude product which has been synthesized in the respective ratio of 1:2:2 of compound 1 , formaldehyde, and morpholine was done using column chromatography with $\mathrm{EtOAc} / \mathrm{MeOH}$ (9:1) as eluent to yield $\mathbf{2 b}$ as colorless needles (5.32 g; quantitative yield) $\mathrm{mp} 88-90{ }^{\circ} \mathrm{C}$ after removing the solvent. IR spectrum $\left(v_{\max } / \mathrm{cm}^{-1}\right)$ : $1113(\mathrm{C}-\mathrm{N}), 1304(\mathrm{C}-\mathrm{O}), 1597(\mathrm{C}=\mathrm{C}), 1669(\mathrm{C}=\mathrm{O})$, $2958\left(\mathrm{CH}_{3}, \mathrm{sp}^{3}\right) .{ }^{1} \mathrm{H}$ NMR (ppm / $\left., 400 \mathrm{MHz}, \mathrm{MeOD}\right): 2.59-2.55(\mathrm{~m}, 11 \mathrm{H}), 3.74-3.72(\mathrm{~m}, 12 \mathrm{H}), 7.83(\mathrm{~s}$, 2H), 7.92 (s, 1H). ${ }^{13} \mathrm{C} \mathrm{NMR}$ (ppm/ $\left.\delta, 100 \mathrm{MHz}, \mathrm{MeOD}\right):$ 24.90, 52.78, 58.18, 66.32, 121.97, 128.25, 130.24, 161.44, 197.94. EIMS, $m / z$ (\% rel. intensity): 334(14) [ $\left.\mathrm{M}^{+}, \mathrm{C}_{18} \mathrm{H}_{26} \mathrm{~N}_{2} \mathrm{O}_{4}\right], 276$ (6), 247 (100), 217 (12), 189 (14), 162 (8), 133 (34), 119 (11), 86 (24), 56 (14).

\subsubsection{1-\{4-Hydroxy-3-[(pyrrolidin-1-yl) methyl]phenyl\}ethan-1-one (3a)}

A ratio of 1:1.5:1.5 of compound 1, formaldehyde, and pyrrolidine, respectively, were used to synthesize 3a. Eluting system of hexanes/EtOAc (6:4), was used to purify the crude product to yield pale-yellow crystals, $(1.72 \mathrm{~g} ; 49 \%), \mathrm{mp} 92-95{ }^{\circ} \mathrm{C}$. IR spectrum $\left(v_{\max } / \mathrm{cm}^{-1}\right): 1191(\mathrm{C}-\mathrm{N}), 1284(\mathrm{C}-\mathrm{O})$, $1595(\mathrm{C}=\mathrm{C}), 1661(\mathrm{C}=\mathrm{O}), 2965\left(\mathrm{CH}_{3}, \mathrm{sp}^{3}\right) .{ }^{1} \mathrm{H}$ NMR (ppm/ $\left.\delta, 400 \mathrm{MHz}, \mathrm{MeOD}\right): 1.99-1.94(\mathrm{~m}, 4 \mathrm{H}), 2.51$ $(\mathrm{s}, 3 \mathrm{H}), 2.92(\mathrm{t}, J=7.0 \mathrm{~Hz}, 4 \mathrm{H}), 4.03(\mathrm{~s}, 2 \mathrm{H}), 6.72(\mathrm{~d}, J=8.5 \mathrm{~Hz}, 1 \mathrm{H}), 7.79(\mathrm{~d}, J=2.3 \mathrm{~Hz}, 1 \mathrm{H}), 7.83(\mathrm{dd}$, $J=8.7$ and $2.4 \mathrm{~Hz}, 1 \mathrm{H}$ ). ${ }^{13} \mathrm{C}$ NMR (ppm/ $\left.8,100 \mathrm{MHz}, \mathrm{MeOD}\right): 23.02,24.67,52.88,57.13,116.53,121.21$, 126.14, 130.22, 130.73, 167.15, 197.75. EIMS, $m / z$ (\% rel. intensity): 219 (13) [ $\left.\mathrm{M}^{+}, \mathrm{C}_{13} \mathrm{H}_{17} \mathrm{NO}_{2}\right], 149$ (5), 133 (3), 106 (2), 91 (2), 84 (9), 77 (4), 70(100), 51 (2).

\subsubsection{1-\{4-Hydroxy-3,5-bis[(pyrrolidin-1-yl) methyl] phenyl\} ethan-1-one (3b)}

The purification of the crude product which has been synthesized in the respective ratio of 1:2:2 of compound $\mathbf{1}$, formaldehyde and pyrrolidine was done using column chromatography with EtOAc/MeOH (9:1) as eluent to yield $3 \mathbf{b}$ as dark red oily liquid $(4.2 \mathrm{~g} ; 86 \%)$. IR spectrum $\left(\gamma_{\max } / \mathrm{cm}^{-1}\right)$ : $1302(\mathrm{C}-\mathrm{O}), 1356(\mathrm{C}-\mathrm{N}), 1597(\mathrm{C}=\mathrm{C}), 1665(\mathrm{C}=\mathrm{O}), 2963\left(\mathrm{CH}_{3}, \mathrm{sp}^{3}\right) .{ }^{1} \mathrm{H}$ NMR $(\mathrm{ppm} / \delta, 400 \mathrm{MHz}$, DMSO- $d_{6}$ ): 1.76 (br s, 8H), 2.47 (s, 3H), 2.57 (br s, 8H), 3.77 (s, 4H), 7.69 (s, 2H). ${ }^{13} \mathrm{C} \mathrm{NMR} \mathrm{(100} \mathrm{MHz,}$ DMSO) ppm: $\delta 23.66,26.67,53.54,55.59,123.68,127.57,128.98,162.09,196.56$. EIMS, $m / z(\%$ rel. intensity): 302 (14) [ $\left.\mathrm{M}^{+}, \mathrm{C}_{18} \mathrm{H}_{26} \mathrm{~N}_{2} \mathrm{O}_{2}\right], 231$ (100), 216 (9), 188 (12), 159 (14), 147 (7), 133 (20), 119 (11), 84 (11), 70 (43), 55 (4).

\subsubsection{1-\{4-Hydroxy-3-[(piperidin-1-yl) methyl] phenyl\} ethan-1-one (4a)}

The crude product of $4 \mathbf{a}$ was obtained from the reaction of the respective ratio 1:1.5:1.5 of compound 1, formaldehyde, and piperidine. The obtained product was purified by using hexanes/EtOAc (6:4) as an eluent to yield $4 a$ as colorless crystals $(2.15 \mathrm{~g}, 58 \%), \mathrm{mp} 82-83{ }^{\circ} \mathrm{C}$. IR spectrum $\left(v_{\max } / \mathrm{cm}^{-1}\right): 1256(\mathrm{C}-\mathrm{N}), 1287(\mathrm{C}-\mathrm{O}), 1594(\mathrm{C}=\mathrm{C}), 1661(\mathrm{C}=\mathrm{O}), 2946\left(\mathrm{CH} 3, \mathrm{sp}^{3}\right) .{ }^{1} \mathrm{H}$ NMR (ppm/ $\left.\delta, 400 \mathrm{MHz}, \mathrm{CDCl}_{3}\right): 1.67-1.52(\mathrm{~m}, 6 \mathrm{H}), 2.53(\mathrm{br} \mathrm{s}, 7 \mathrm{H}), 3.75(\mathrm{~s}, 2 \mathrm{H}), 6.84(\mathrm{~d}, J=8.4 \mathrm{~Hz}, 1 \mathrm{H}), 7.68$ (s, 1H), $7.80(\mathrm{~d}, J=8.4 \mathrm{~Hz}, 1 \mathrm{H}), 11.41(\mathrm{br} \mathrm{s}, 1 \mathrm{H}) .{ }^{13} \mathrm{C} \mathrm{NMR}\left(\mathrm{ppm} / \delta, 100 \mathrm{MHz}, \mathrm{CDCl}_{3}\right): 23.71,25.6,26.22$, 53.73, 61.51, 115.93, 121.06, 128.73, 129.35, 130.24, 163.32, 196.86. EIMS, $m / z$ (\% rel. intensity): 233 (10) $\left[\mathrm{M}^{+}, \mathrm{C}_{14} \mathrm{H}_{19} \mathrm{NO}_{2}\right], 149$ (4), 133 (2), 106 (1), 98 (5), 84 (100), 77 (3), 56 (2).

\subsubsection{1-\{4-Hydroxy-3,5-bis[(piperidin-1-yl) methyl] phenyl\} ethan-1-one (4b)}

The crude product resulted from the reaction of the respective ratio 1:2:2 of compound 1, formaldehyde, and piperidine was purified using hexanes/EtOAc (3:7) as eluent to yield $\mathbf{4 b}$ as pale-yellow crystals mp $93-96{ }^{\circ} \mathrm{C}(5 \mathrm{~g}, 94 \%)$. IR spectrum $\left(v_{\max } / \mathrm{cm}^{-1}\right)$ : $1300(\mathrm{C}-\mathrm{O}), 1349(\mathrm{C}-\mathrm{N}), 1594$ 
$(\mathrm{C}=\mathrm{C}), 1669(\mathrm{C}=\mathrm{O}), 2925\left(\mathrm{CH}_{3}, \mathrm{sp}^{3}\right) .{ }^{1} \mathrm{H}$ NMR (ppm / $\left.8,400 \mathrm{MHz}, \mathrm{DMSO}\right): 1.53-1.42(\mathrm{~m}, 12 \mathrm{H}), 2.46-2.43$ $(\mathrm{m}, 11 \mathrm{H}), 3.6(\mathrm{~s}, 4 \mathrm{H}), 5.51$ (br s, $1 \mathrm{H}), 7.68(\mathrm{~s}, 2 \mathrm{H}) .{ }^{13} \mathrm{C} \mathrm{NMR}$ (ppm/ $\left./, 100 \mathrm{MHz}, \mathrm{DMSO}\right): 24.13,25.90$, 26.65, 53.84, 58.65, 123.01, 127.92, 129.27, 161.97, 196.59. EIMS, $m / z$ (\% rel. intensity): 330 (14) $\left[\mathrm{M}^{+}\right.$, $\mathrm{C}_{20} \mathrm{H}_{30} \mathrm{~N}_{2} \mathrm{O}_{2}$ ], 245 (100), 228 (4), 202 (10), 147 (4), 133 (13), 119 (4), 98 (4), 84 (24), 55 (3).

\subsubsection{1-\{3-[(Diethylamino) methyl]-4-hydroxyphenyl\} ethan-1-one (5a)}

The crude product of $\mathbf{5 a}$ was obtained from the reaction of the respective ratio 1:2:2. of compound 1, formaldehyde, and diethylamine. The product was purified by column chromatography using hexanes/EtOAc (6:4) to yield $5 \mathbf{a}$ as a yellow oily liquid (3.53 $\mathrm{g}$, quantitative yield). IR spectrum $\left(v_{\max } / \mathrm{cm}^{-1}\right): 1280(\mathrm{C}-\mathrm{N}), 1357(\mathrm{C}-\mathrm{O}), 1589(\mathrm{C}=\mathrm{C}), 1667(\mathrm{C}=\mathrm{O}), 2972\left(\mathrm{CH}_{3}, \mathrm{sp}^{3}\right) .{ }^{1} \mathrm{H} \mathrm{NMR}(\mathrm{ppm} / \delta$, $\left.400 \mathrm{MHz}, \mathrm{CDCl}_{3}\right): 1.07(\mathrm{t}, J=7.0 \mathrm{~Hz}, 6 \mathrm{H}), 2.46(\mathrm{~s}, 3 \mathrm{H}), 2.59(\mathrm{q}, J=7.0 \mathrm{~Hz}, 4 \mathrm{H}), 3.77(\mathrm{~s}, 2 \mathrm{H}), 6.74(\mathrm{~d}$, $J=8.4 \mathrm{~Hz}, 1 \mathrm{H}), 7.60(\mathrm{~s}, 1 \mathrm{H}), 7.73(\mathrm{~d}, J=8.4 \mathrm{~Hz}, 1 \mathrm{H}), 11.47$ (br s, $1 \mathrm{H}) \cdot{ }^{13} \mathrm{C} \mathrm{NMR}(\mathrm{ppm} / \delta, 100 \mathrm{MHz}$, $\left.\mathrm{CDCl}_{3}\right): 10.99,26.08,46.22,56.61,115.87,121.68,128.51,128.95,130.06,163.77,196.74$. EIMS, $m / z(\%$ rel. intensity): 221 (5) [ $\left.\mathrm{M}^{+}, \mathrm{C}_{13} \mathrm{H}_{19} \mathrm{NO}_{2}\right], 206$ (6), 149 (8), 132 (2), 106 (1), 77 (2), 58 (100).

\subsection{X-ray Structure Determination}

Crystal data, data collection, and structure refinement details are summarized in Table 2. Crystallographic data for 2a and 3a were collected on Bruker D8 Venture diffractometer; cell refinement-Bruker SAINT, data reduction-Bruker SAINT [31]; program(s) used to solve and refine structures-SHELXT 2014/5 and SHELXL2014/7 [32,33]; molecular graphics-ORTEP [34,35]; and software used to prepare material for publication-WinGX [37]. All non-hydrogen atoms were refined anisotropically. The hydrogen atoms at the oxygen atoms were located from Fourier map, at carbon and nitrogen atoms placed in calculated positions and refined as rigid atoms. All calculations were performed on PC using WinGX program. Data collection: images were indexed, integrated, and scaled using the APEX3 data reduction package [31]. All figures were made using the program ORTEP and Diamond program [32-36].

\subsection{Computations}

Hirshfeld surface analysis (HSA) and 2D fingerprint plots calculations were carried via $\mathrm{d}_{\text {norm }}$ surface property with rescale using CRYSTAL EXPLORER 3.0 program [43]. Normalized distances, $d_{\text {norm }}$, based on $d_{i}$ and $d_{e}$, are calculated for each point on the surface. HSA mapped over $d_{\text {norm }}$ generates a surface with red, blue, and white areas-red spots correspond to closer contacts (the sum of van der Waals radii and $d_{\text {norm }}$ is negative), blue spots correspond to longer contacts (the sum of van der Waals radii and $d_{\text {norm }}$ is positive) and white spots correspond to $d_{\text {norm }}$ values around van der Waals separations. The 2D fingerprint plots provide information about the frequency of each $d_{i}$ and $d_{e}$ combination across all points on HS. The green, blue, and gray colors correspond to interactions with large contribution, with moderate contribution, and without contribution to HS area, respectively. The identical features along 2D plots diagonal correspond to mirrored internal-external atomic contacts (e.g., $\mathrm{O} \ldots \mathrm{H}$ and $\mathrm{H} \ldots \mathrm{O}$ contacts).

\section{Conclusions}

It can be concluded that this novel alternative methodology offers significantly less synthesis time with competitive product yield of Mannich bases in the absence of any catalyst. The X-ray crystal structure of 2a shows an intramolecular hydrogen bonding and displays a chair conformation for the morpholine fragment and, unlike 3a, exhibits intermolecular hydrogen bonding. The HAS shows that the intermolecular interactions are dominated by $\mathrm{H}$... H interaction for both compounds, though for $\mathbf{2 a}$ it is stronger. Moreover, $2 \mathrm{D}$ fingerprint plots confirm that $\pi-\pi$ stacking is only present for $\mathbf{2 a}$. 
Supplementary Materials: Supplementary Materials are available online.

Author Contributions: Conceptualization, A.A.A., S.Y.A. and N.B., Supervision; G.A.; Methodology, All authors, mainly, G.A.; Writing-Review \& Editing; D.L. and M.A.S; X-ray work, A.A.; HSA work.

Funding: This research received no external funding.

Acknowledgments: Ghadah Aljohani and Norazah Basar gratefully acknowledge support by Taibah University and Universiti Teknologi. Musa A. Said thanks the Alexander von Humboldt foundation for the valuable and continuous support.

Conflicts of Interest: The authors declare no conflict of interest.

\section{References}

1. Tramontini, M. Advances in the Chemistry of Mannich Bases. Synthesis 1973, 12, 703-775. [CrossRef]

2. Filho, J.F.A.; Lemos, B.C.; de Souza, A.S.; Pinheiro, S.; Greco, S.J. Multicomponent Mannich reactions: General aspects, methodologies and applications. Tetrahedron 2017, 73, 6977-7004. [CrossRef]

3. Teissier, E.; Zandomeneghi, G.; Loquet, A.; Lavillette, D.; Lavergne, J.-P.; Montserret, R.; Cosset, F.-L.; Böckmann, A.; Meier, B.H.; Penin, F.; et al. Mechanism of Inhibition of Enveloped Virus Membrane Fusion by the Antiviral Drug Arbidol. PLoS ONE 2011, 6, e15874. [CrossRef] [PubMed]

4. Boriskin, Y.; Leneva, I.; Pecheur, E.-I.; Polyak, S. Arbidol: A Broad-Spectrum Antiviral Compound that Blocks Viral Fusion. Curr. Med. Chem. 2008, 15, 997-1005. [CrossRef] [PubMed]

5. Fernández-Bachiller, M.I.; Pérez, C.; González-Muñoz, G.C.; Conde, S.; López, M.G.; Villarroya, M.; García, A.G.; Rodríguez-Franco, M.I. Novel Tacrine-8-Hydroxyquinoline Hybrids as Multifunctional Agents for the Treatment of Alzheimer's Disease, with Neuroprotective, Cholinergic, Antioxidant, and Copper-Complexing Properties. J. Med. Chem. 2010, 53, 4927-4937. [CrossRef] [PubMed]

6. Qin, J.; Lan, W.; Liu, Z.; Huang, J.; Tang, H.; Wang, H. Synthesis and biological evaluation of 1, 3-dihydroxyxanthone mannich base derivatives as anticholinesterase agents. Chem. Cent. J. 2013, 7, 78. [CrossRef] [PubMed]

7. Alonso, D.; Dorronsoro, I.; Rubio, L.; Muñoz, P.; García-Palomero, E.; Del Monte, M.; Bidon-Chanal, A.; Orozco, M.; Luque, F.J.; Castro, A.; et al. Donepezil-tacrine hybrid related derivatives as new dual binding site inhibitors of AChE. Bioorg. Med. Chem. 2005, 13, 6588-6597. [CrossRef]

8. Malhotra, M.; Sharma, R.; Sanduja, M.; Kumar, R.; Jain, E.; Deep, A. Synthesis, characterization and evaluation of Mannich bases as potent antifungal and hydrogen peroxide scavenging agents. Acta Pol. Pharm. Drug Res. 2012, 69, 355-361.

9. Buravlev, E.V.; Shevchenko, O.G.; Kutchin, A.V. Synthesis and membrane-protective activity of novel derivatives of $\alpha$-mangostin at the C-4 position. Bioorg. Med. Chem. Lett. 2015, 25, 826-829. [CrossRef]

10. Aeluri, R.; Alla, M.; Polepalli, S.; Jain, N. Synthesis and antiproliferative activity of imidazo[1,2-a]pyrimidine Mannich bases. Eur. J. Med. Chem. 2015, 100, 18-23. [CrossRef]

11. Issa, S.; Walchshofer, N.; Kassab, I.; Termoss, H.; Chamat, S.; Geahchan, A.; Bouaziz, Z. Synthesis and antiproliferative activity of oxazinocarbazole and $\mathrm{N}, \mathrm{N}$-bis(carbazolylmethyl)amine derivatives. Eur. J. Med. Chem. 2010, 45, 2567-2577. [CrossRef] [PubMed]

12. Sahoo, S.; Joseph, T.; Halligudi, S.B. Mannich reaction in Brönsted acidic ionic liquid: A facile synthesis of $\beta$-amino carbonyl compounds. J. Mol. Catal. A Chem. 2006, 244, 179-182. [CrossRef]

13. Müller, R.; Goesmann, H.; Waldmann, H. N,N-Phthaloylamino Acids as Chiral Auxiliaries in Asymmetric Mannich-Type Reactions. Angew. Chem. Int. Ed. 1999, 38, 184-187. [CrossRef]

14. Xie, L.-H.; Cheng, J.; Luo, Z.-W.; Lu, G. Mannich Reaction of Indole with Cyclic Imines in Water. Tetrahedron Lett. 2018, 59, 457-461. [CrossRef]

15. Zhang, X.; Yin, S.; Qiu, R.; Xia, J.; Dai, W.; Yu, Z.; Au, C.-T.; Wong, W.-Y. Synthesis and structure of an air-stable hypervalent organobismuth (III) perfluorooctanesulfonate and its use as high-efficiency catalyst for Mannich-type reactions in water. J. Organomet. Chem. 2009, 694, 3559-3564. [CrossRef]

16. Abedini-Torghabeh, J.; Eshghi, H.; Bakavoli, M.; Rahimizadeh, M. PPh3-catalyzed Mannich reaction: A facile one-pot synthesis of $\beta$-amino carbonyl compounds under solvent-free conditions at room temperature. Res. Chem. Intermed. 2015, 41, 3649-3658. [CrossRef]

17. Wei, C.; Li, C.J. A highly efficient three-component coupling of aldehyde, alkyne, and amines via C-H activation catalyzed by gold in water. J. Am. Chem. Soc. 2003, 125, 9584-9585. [CrossRef] 
18. Li, Z.; Ma, X.; Liu, J.; Feng, X.; Tian, G.; Zhu, A. Silica-supported aluminum chloride: A recyclable and reusable catalyst for one-pot three-component Mannich-type reactions. J. Mol. Catal. A Chem. 2007, 272, 132-135. [CrossRef]

19. Nagarajan, S.; Kandasamy, E. Reusable 1,2,4-Triazolium Based Brønsted Acidic Room Temperature Ionic Liquids as Catalyst for Mannich Base Reaction. Catal. Lett. 2014, 144, 1507-1514. [CrossRef]

20. Zhao, G.; Jiang, T.; Gao, H.; Han, B.; Huang, J.; Sun, D. Mannich reaction using acidic ionic liquids as catalysts and solvents. Green Chem. 2004, 6, 75-77. [CrossRef]

21. Lehmann, F.; Pilotti, Å.; Luthman, K. Efficient large scale microwave assisted Mannich reactions using substituted acetophenones. Mol. Divers. 2003, 7, 145-152. [CrossRef] [PubMed]

22. Kabalka, G.W.; Zhou, L.-L.; Wang, L.; Pagni, R.M. A microwave-enhanced, solventless Mannich condensation of terminal alkynes and secondary amines with para-formaldehyde on cuprous iodide doped alumina. Tetrahedron 2006, 62, 857-867. [CrossRef]

23. Rao, G.V.; Reddy, P.N.; Reddy, Y.T.; Kumar, V.N.; Rajitha, B. Synthesis of benzo [b] furan Mannich bases under solventless, PTSA/PTC catalytic conditions assisted by microwave irradiation. Indian J. Chem. 2005, 44, 1109-1111. [CrossRef]

24. McLean, N.J.; Tye, H.; Whittaker, M. Microwave assisted Petasis boronic-Mannich reactions. Tetrahedron Lett. 2004, 45, 993-995. [CrossRef]

25. Mete, E.; Gul, H.I.; Bilginer, S.; Algul, O.; Topaloglu, M.E.; Gulluce, M.; Kazaz, C. Synthesis and Antifungal Evaluation of 1-Aryl-2-dimethyl-aminomethyl-2-propen-1-one Hydrochlorides. Molecules 2011, 16, 4660-4671. [CrossRef] [PubMed]

26. Akhter, M.; Habibullah, S.; Hasan, S.M.; Alam, M.M.; Akhter, N.; Shaquiquzzaman, M. Synthesis of some new 3,4-dihydro-2H-1,3-benzoxazines under microwave irradiation in solvent-free conditions and their biological activity. Med. Chem. Res. 2011, 20, 1147-1153. [CrossRef]

27. Sreevalli, W.; Ramachandran, G.; Madhuri, W.; Sathiyanarayanan, K.I. ChemInform Abstract: Green Trends in Mannich Reaction. ChemInform 2015, 46, 97-115. [CrossRef]

28. Mavandadi, F.; Pilotti, Å. The impact of microwave-assisted organic synthesis in drug discovery. Drug Discov. Today 2006, 11, 165-174. [CrossRef]

29. Dong, X.; Liu, T.; Chen, J.; Ying, H.; Hu, Y. Microwave-Assisted Mannich Reaction of 2-Hydroxy-chalcones. Synth. Commun. 2009, 39, 733-742. [CrossRef]

30. Reddy, M.V.B.; Su, C.R.; Chiou, W.F.; Liu, Y.N.; Chen, R.Y.H.; Bastow, K.F.; Lee, K.H.; Wu, T.S.; Bhaskar, M.V.; $\mathrm{Su}$, C.R.; et al. Design, synthesis, and biological evaluation of Mannich bases of heterocyclic chalcone analogs as cytotoxic agents. Bioorg. Med. Chem. 2008, 16, 7358-7370. [CrossRef]

31. APEX2 (Version 2.1), SAINTPlus. Data Reduction and Correction Program (Version 7.31A, Bruker Advansed X-ray Solutions; BrukerAXS Inc.: Madison, WI, USA, 2006.

32. Sheldrick, G.M. Crystal structure refinement with SHELXL. Acta Crystallogr. Sect. C Struct. Chem. 2015, 71, 3-8. [CrossRef] [PubMed]

33. Sheldrick, G.M. Sheldrick SHELXS-97_Program for the Solution of Crystal Structures; University of Gottingen: Gottingen, Germany, 1997.

34. Johnson, C.K. ORTEP II, Report ORNL-5138; Oak Ridge National Laboratory: Oak Ridge, TN, USA, 1976.

35. Farrugia, L.J. UCr ORTEP-3 for Windows-A version of ORTEP-III with a Graphical User Interface (GUI). J. Appl. Crystallogr. 1997, 30, 565. [CrossRef]

36. Brandenburg, K.; Putz, H. Diamond-Crystal and Molecular Structure Visualization; Crystal Impact: Bonn, Germany, 2012.

37. Farrugia, L.J. WinGX and ORTEP for Windows: An update. J. Appl. Crystallogr. 2012, 45, 849-854. [CrossRef]

38. Taylor, R.; Kennard, O. Comparison of X-ray and Neutron Diffraction Results for the N-H ... O-C Hydrogen Bond. Acta Crystallogr. Sect. B 1983, 39, 133-138. [CrossRef]

39. Jeffrey, G.A.; Lewis, L. Cooperative aspects of hydrogen bonding in carbohydrates. Carbohydr Res. 1978, 60, 179-182. [CrossRef]

40. Rivera, A.; Duarte, Y.; González-Salas, D.; Ríos-Motta, J.; Zaragoza, G. X-ray and hydrogen-bonding Properties of 1-((1H-benzotriazol-1-yl)methyl) naphthalen-2-ol. Molecules 2009, 14, 1234-1244. [CrossRef] [PubMed]

41. Desiraju, G.R. Supramolecular Synthons in Crystal Engineering-A New Organic Synthesis. Angew. Chem. Int. Ed. Engl. 1995, 34, 2311-2327. [CrossRef] 
42. Mozzchukhin, A.O.; Macharashvili, A.A.; Shklover, V.E.; Struchkov, Y.T.; Shipov, A.G.; Sergeev, V.N.; Artamkin, S.A.; Pestunovich, S.V.; Baukov, Y.I. Crystal and molecular structures of (O-Ge)-chelate 1-(dimethylchlorogermylmethyl)pyrrolidone-2 and 1-(dimethylchlorogermylmethyl)piperidone-2, and of (N-Ge)-chelate O-(dimethylchlorogermylmethyl)- $\delta$-valerolactim and 2-(chlorodimethylgermylmethylthio)pyrro. J. Organomet. Chem. 1991, 408, 305-322. [CrossRef]

43. Wolff, S.K.; Grimwood, D.J.; McKinnon, J.J. Crystal Explorer 3.0; University of Westren Australia: Perth, Australia, 2007.

Sample Availability: Atomic coordinates, bond lengths, bond angles and thermal parameters have been deposited at the Cambridge Crystallographic Data Centre (CCDC). These data can be obtained free of charge via www.ccdc. cam.uk/conts / retrieving.html (or from the CCDC, 12 Union Road, Cambridge CB2 1EZ, UK; fax: +44 1223336 033; or deposit@ ccdc.cam.ac.uk). Any requests to the CCDC for data should quote the full literature citation and CCDC reference numbers for $2 \mathbf{a}$ and $3 \mathbf{a} 1832359,1832328$ respectively.

(C) 2019 by the authors. Licensee MDPI, Basel, Switzerland. This article is an open access article distributed under the terms and conditions of the Creative Commons Attribution (CC BY) license (http:/ / creativecommons.org/licenses/by/4.0/). 